\title{
How community structures of time and opportunity shape adolescent sexual behavior in South Africa
}

Carol E. Kaufman

Shelley Clark

Ntsiki Manzini

Julian May

Follow this and additional works at: https://knowledgecommons.popcouncil.org/departments_sbsr-pgy

Part of the Demography, Population, and Ecology Commons, Family, Life Course, and Society Commons, and the International Public Health Commons How does access to this work benefit you? Let us know!

\section{Recommended Citation}

Kaufman, Carol E., Shelley Clark, Ntsiki Manzini, and Julian May. 2002. "How community structures of time and opportunity shape adolescent sexual behavior in South Africa," Policy Research Division Working Paper no. 159. New York: Population Council. 
How Community Structures

$>$ of Time and Opportunity Shape Adolescent Sexual Behavior in South Africa

$\pm$

Carol E. Kaufman

Shelley Clark

Ntsiki Manzini

Julian May 


\title{
How Community Structures of Time and Opportunity Shape Adolescent Sexual Behavior in South Africa
}

\author{
Carol E. Kaufman \\ Shelley Clark \\ Ntsiki Manzini \\ Julian May
}

Carol E. Kaufman is Project Director, University of Colorado Health Sciences Center. Shelley Clark is Assistant Professor, University of Chicago. Ntsiki Manzini is Junior Researcher and Julian May is Associate Professor, University of Natal-Durban.

This research has been generously supported through a grant from the Rockefeller Foundation, USAID funding through the HORIZONS and FOCUS/MEASURE/EVALUATION projects, and by the Mellon Foundation. Correspondence should be directed to carol.kaufman@uchsc.edu 


\begin{abstract}
Recently, South Africa has led the world in rates of HIV/AIDS infection. Particularly among young adults, the prevalence of HIV has soared, now reaching 25 percent. The statistics suggest a high level of unprotected sex and risky sexual behavior even in the midst of high levels of knowledge. Research has focused on the dynamics of individuals' and partners' sexual decisionmaking. Little is known, however, about the larger context in which those decisions are made. What are the everyday experiences that influence risk-taking? Are young people with little to do more likely to engage in risky behavior? Do community opportunities of schooling, work, and other activities make a difference? This study employs time-use data and data on education, work, and activities of adolescents collected from a representative sample of 2,992 young people aged 14 to 22 living in KwaZulu-Natal, South Africa, to explore these questions. Analyses of time use indicate that African and Indian girls spend twice as much time engaged in unpaid domestic work as do their male counterparts, whereas white boys spend the most time of those studied in paid positions. Africans, both boys and girls, report studying fewer hours than other racial groups. For girls, levels of education in the community were positively associated with not having had sex in the last 12 months. Levels of wages in communities were positively associated with condom use for both boys and girls. Levels of sports activity in communities had a positive association with risk-taking among boys and a negative one among girls.
\end{abstract}

This material may not be reproduced without written permission from the authors. For a list of Policy Research Division Working Papers, including those available for downloading in PDF format, see www.popcouncil.org/publications/wp/prd/rdwplist.html. 
Multifactorial approaches to explicating influences on risky sexual behavior among adolescents have received increased attention in recent research (Rutter 1993; Resnick et al. 1997; Kirby 2001). Communities (Brookes-Gunn et al. 1997; Mullan Harris and Ryan 2001), families and schools (Jaccard et al. 1996; Resnick et al. 1997), and peers (NCPTP 1999) have had demonstrable effects on several dimensions of adolescents' risky sexual behavior. These research efforts have been limited to developed countries, however, and largely to the United States. The form or scope of the influences likely to affect adolescents' sexual behavior in developing or transitional countries has received scant attention. The void is particularly disturbing because the highest levels of sexually transmitted diseases, including HIV/AIDS, and of early age of childbearing exist in these regions (Mensch et al. 1998; UNAIDS 2001). Cross-national research has documented trends in knowledge, attitudes, and behaviors, primarily at the individual level (Blanc and Way 1998; Singh 1998; Ahmed et al. 2001), yet we know little about the contextual factors shaping potentially fatal sexual decisions and behaviors in countries in which community and cultural influences might matter the most.

The present analysis uses data from South Africa to demonstrate the importance of community opportunities related to school, work, and other activities for the risky sexual behaviors of young people. South Africa presents a strong case for considering contextual effects on behavior. During the last decade, the prevalence of HIV among the young has soared in that country. In 1994, 7 percent of adolescents aged 15 to 19 were HIV positive; in 2000, that number had increased to 16 percent. The increased risk of transmission with age is shown by trends for those in their twenties: An astounding 31 percent of those aged 25 to 29 in 2000 were HIV positive (South African Department of Health 2001). Although the HIV epidemic has featured prominently in research and in the media, consequences of risky sexual behavior are not limited to disease. More than 35 percent of 19-year-old South African girls have been pregnant at least once (SAMRC et al. 1999). These statistics suggest a high level of unprotected sex and risky sexual behavior among young South Africans, and those who are about to assume adult roles and responsibilities appear to be particularly vulnerable.

A number of ethnographic studies have investigated what might be considered the proximate social determinants of sexual activity, those forces that exert influence on 
individuals and couples, for example, reproductive knowledge, communication between partners, and perceived risk (Varga 1996, 1997, 1999; Wood and Jewkes 1997; MacPhail and Campbell 2001). Each of these studies postulates the importance of contextual factors on adolescent behavior in South Africa. This concern is reiterated by Gilbert and Walker (2002), who argue that the country's history of social inequality-often manifested in geographic differentials persisting from apartheid-era racial boundaries-has patterned the spread of the disease and has underpinned the perceptions and prejudices in the prevention and treatment of the disease. Indeed, for many of the country's adolescents, the everyday manifestation of a history of political strife and economic hardship may be boredom, disengagement, and risk-taking (Roos et al. 1995; LeClerc-Madlala 1997). Yet, we know too little about how community life is woven into the content and structure of the everyday life of adolescents, or how that weave might influence safe or unsafe sexual practices. We know even less about how this varies by race or by sex. Understanding patterns of knowledge or communication among the young is useful only if it can be placed in a larger context: Adolescents act differentially upon what they know or can communicate according to the opportunities or limitations of school, work, and play.

\section{Adolescents' Risky BeHAVIOR In THE COMMUnity CONTEXT}

Theories describing the relationship of available opportunities and time use with adolescents' sexual behavior have appeared in the literature only recently. In the following review, we assess research that situates adolescents' experience in daily life and that considers the relationship of various domains of daily life to sexual risk-taking. We also examine the larger literature studying the effects of community on adolescents' sexual behavior. Our focus is primarily on cross-national research, particularly from sub-Saharan Africa, broadening to include research from other regions and countries, including the US, when appropriate.

Schooling for many adolescents is a formative aspect of this time of life. Indeed, the educational attainment and achievement of children and young adults are the focus of a large body of research. More recently researchers have considered critically the relationship of schooling to sexual behavior (Lloyd and Mensch 1999; Lloyd et al. 2000). 
As Lloyd and Mensch (1999) point out, the educational literature often considers schools to be a conservative force that entrenches gender roles and reproduces racial or economic disparities through the content and form of instruction. Schools may also be a locus of sexual harassment and an environment providing opportunities for sexual contact. On the other hand, schools provide supervised time, thereby offering students, especially girls, an alternative to higher-risk activities available outside the schoolyard gates (Nichols et al. 1987; Ajayi et al. 1991; Zabin and Kiragu 1998). Schools may also provide adolescents with the psychological and social tools with which to nurture and negotiate healthy relationships and encourage growth in self-esteem so that they can communicate better with their partners about safer sex practices. Empirical evidence supporting or refuting these contradictory descriptions of school time and adolescence remains slim. For example, although studies tend to show a negative relationship between school enrollment or educational attainment and risky behavior (e.g., Meekers and Ahmed 1999), few studies account appropriately for the ambiguous causality between the two (Mensch et al. 1998).

Although schooling might occupy a significant amount of adolescents' time, after-school hours, the time when teenagers have the greatest opportunity to engage in risky behavior, are often unstructured and unsupervised (Boyer and Kegeles 1991; Flannery et al. 1999; Larson and Verma 1999). Drawing on results from studies conducted in the United States, Pawelko and Magafas (1997) argue that the young seem to make poor choices in the use of their time outside of school. For example, Flannery and colleagues (1999) found that boys and girls who spent time after school with peers and without adult supervision reported higher levels of risky behavior and susceptibility to peer pressure compared with adolescents who spent time at home with a parent. Similarly, Larson and Verma (1999) found an association between "driving around in cars" and delinquent behaviors. These studies provide some evidence of association, but they did not investigate the causal mechanisms relating the use of free time to risky behavior. Jemmott and Jemmott (1993) - referring also to the experience of adolescents in the US - propose that the increased use of alcohol and drugs associated with unsupervised free time raised the likelihood of engaging in risky sexual behavior. A number of other studies conducted in the US also found a clear and positive relationship between alcohol 
and drug use and risky sexual behavior (Hingson et al. 1990; Langer and Tubman 1997; Langer and Girad 1999).

In many developing countries, after-school hours do not represent free time; they are spent at work, often unpaid or domestic work. The 1997 State of the World's Children report (UNICEF 1998) estimated that 400 million children work at jobs that include unpaid labor. In South Africa, for example, an estimated 36 percent of 5-17-yearolds worked at least three hours for remuneration, five hours in school, and seven hours in unpaid labor per week (International Labour Organization 1999). Most studies, however, focus on wage work, either in the formal or informal sector (Esim et al. 1999), even though wage work is uncommon among adolescent girls (Mensch et al. 1998). Moreover, most research considering adolescents and work focuses on the extent of participation, wages, and working conditions. Few consider the link between work in any form and sexual behavior (see Amin et al. 1998, however, for an excellent examination of the delay of marriage and childbearing among young female garment workers in Bangladesh).

Research concerning community effects on adolescent behavior has progressed much farther in developed countries. In a recent review of the US literature, Kirby (1999) found a number of studies that include the effects of community characteristics on adolescent sexual behavior. His review suggests that the adolescents most likely to take sexual risks live in communities that endure high levels of crime, high residential turnover, extreme rates of poverty, elevated unemployment rates, and low educational levels. The emphasis on structural aspects of community life, primarily the aspects considered in research on sexual behavior, is in part the result of the availability of data drawn from census information and other administrative sources. Theoretical developments in community effects on adolescents' behavior, however, have challenged researchers to move beyond these static measures. Theories of community effects have been rooted in the literature on US poverty, have often drawn on social capital theory (Coleman 1988), and have been conceptualized in terms of both the structural characteristics (Brewster 1994; Darling and Steinberg 1997; Duncan et al. 1997; Gephart 1997; Mullan Harris and Ryan 2001) and the collective lifestyles (Frohlich et al. 2002) of communities in which children and young people are socialized. Studies that have included multidimen- 
sional measures of communities find that structures of opportunities within communities are important to children's and adolescents' development. They also find that the effects of such structures often are mediated by family processes and by a family's ability to draw on resources within the community.

In the developing world, theoretical impetus for contextual-effects approaches to individual behavior has existed for some time (Casterline 1982 and 1985; Tsui 1985). Indeed, the approach has been used with increasing frequency in the demographic literature, especially to evaluate mortality risks or health-care service provision (Curtis and Steele 1996; DeGraff et al. 1997; Magadi et al. 2001). Research that has modeled the effects of the community context on contraceptive use and sexual behavior typically uses samples of women aged 15 to 49 (Entwisle et al. 1996; Steele et al. 1996; Steele et al. 1999; Ali 2001). A few exceptions exist. Gupta (2000) estimated multilevel models of three rounds of Demographic and Health Survey (DHS) data from Brazil and found that religious involvement, exposure to television, and education had a statistically significant effect on adolescents' sexual initiation and use of contraceptives in the expected directions.

Studies of contextual effects on reproductive behavior are similarly scarce. Kaufman (1998) found evidence that community-level economic status and migration patterns affected contraceptive use among black South African women aged 15-49 during the apartheid era. The association of sexual risk and disease outcomes with individuals' community involvement was explored recently by Campbell et al. (2002). In that study, for which both biological and behavioral measures were collected from a representative sample of 15-to-44-year-olds from a mining town near Johannesburg, belonging to a sports club decreased the likelihood of using a condom with a casual partner for young women aged 15-24, but also decreased the likelihood of being HIV-positive for young men and women. Being involved with a youth group also had a statistically significant negative effect on young women's likelihood of being HIV-positive and on having had a casual partnership in the last year (no such effect was found for young men). In summary, the thin evidence concerning contextual effects on adolescents' behavior is, at best, uneven; by and large, the evidence is absent. For South Africa, a country in which the spread of HIV infection is extensive among young people, an improved understanding of this relationship is critical to coherent and appropriate program and policy development. 
In the present analysis, we place sexual risk in the context of South African community life. The extent to which adolescents perceive community opportunities and then take advantage of them will shape their sexual risk-taking behaviors. Brewster (1994: 604), in her study of sexual transition among young black women in the US, describes this approach in the following way: "The opportunity structure and the normative context [of local communities] are posited to affect sexual and contraceptive behavior indirectly through their influence on the young woman's beliefs... [and her motivations] to avoid the possible consequences of unprotected intercourse." In short, an adolescent's use of time - taking advantage of or passing up available opportunities-provides the frame through which opportunities may affect individual behavior. We expect, for example, that young people who spend a great deal of time "hanging out" are more likely to engage in sexual risk-taking. Where many opportunities exist for young people to become involved in community activities, however, adolescents are likely to be more motivated to limit risk-taking, whether or not they themselves participate in the activities. Those who live in communities where many of their peers attend school are likely to see education as an expectation or as a promise for the future and will be less likely to engage in risk-taking behavior. Work and employment prospects are likely to operate in a similar manner. Those who live in areas where others of their own age are working and earning a reasonable income may perceive that opportunities for employment exist, and thus they may be less willing to take sexual risks.

To evaluate these hypotheses fully, we first examine daily life at school, work, and other activities among South African young adults. From this perspective, we consider how the variations in opportunities offered by families and communities influence adolescents' sexual risk-taking.

\section{SETTING, DATA, AND Methods}

Data for this analysis are drawn from the first round of a longitudinal study of young adults in KwaZulu-Natal, South Africa, entitled Transitions to Adulthood in the Context of AIDS in South Africa (Rutenberg et al. 2001). KwaZulu-Natal is situated on the east coast along the Indian Ocean, and, with a population of 8.4 million, it is the most populous province in South Africa. The province is about 45 percent urban and 
includes Durban, the largest port and third-largest city in the country. Just under onefourth of the country's African population resides in the province, and within its borders, Africans, primarily Zulu-speaking, make up approximately 80 percent of the total. The Indian population, originally brought to the province as indentured servants in the nineteenth century to work on sugar plantations, are the next-largest group, just under 10 percent of the total, followed by whites at 7 percent (Central Statistical Service 1997).

For this study, two districts—Durban Metro and Mtunzini-were selected within KwaZulu-Natal in order to include urban, transitional, and rural regions. Within these two districts, the study used a modified multistage cluster sample to represent all racial groups and classes. The first round of data collection, on which the present analysis is based, included individual interviews with 3,052 adolescents aged 14 to 22 . These interviews were conducted in 113 randomly selected census enumeration areas during a sixweek period from 16 September to 30 October 1999. The interviews included a variety of questions on sexual health and behaviors as well as on the context of adolescent life, including schooling, work, and other activities. The complete educational history of each adolescent was recorded, along with current enrollment status. Questions were asked about work experiences and participation in organizations. Information concerning communities is based on aggregated individual data because no equivalent data are available from other sources. Finally, the analysis draws from time-use data. Each adolescent was asked to complete a 24-hour time-use schedule, recording on an hourly basis the activities in which she or he was involved, for example, time at school, domestic work, watching television, or participating in sports. Respondents were asked about the preceding 24 hours (beginning at midnight the previous day). Interviewers recorded whether that period of recall fell on a weekday, weekend, or holiday. In combination, these data provide insight into the daily structure of adolescents' lives. Rutenberg et al. (2001) describe the study and first-wave results.

In the present analysis, we focus on two aspects of sexual risk-taking: having had sex in the last 12 months and condom use at last sex within the last 12 months. These two behaviors represent critical points on which sexual risk may turn. Abstaining from sex reduces to zero the probability of disease transmission via sexual contact. Debate 
still exists on the viability of condom use for effective reduction of disease transmission. In a recent review of the findings on condom effectiveness from the National Institute of Allergy and Infectious Diseases (NIAID 2001), however, condoms were deemed effective if used properly and consistently (Cates 2001). A vast literature exists on condom use in many settings, but none of these studies has considered community effects on adolescents' behavior. ${ }^{1}$ The literature on sexual initiation and frequency of intercourse is growing quickly, although few of these consider community effects, and those that do are based on US samples (Billy et al. 1994; Ku et al. 1998; Mullan Harris 2001). None has considered the incidence of recent sexual abstinence, regardless of sexual experience. These two behaviors, then, capture the essence of sexual risk for adolescents. Condom use is considered here as a two-stage decisionmaking process. The first step is whether or not to have sex; the second, conditional on having sex, is whether or not to use a condom. ${ }^{2}$ The variables are derived from a series of questions about sexual activities. The first question asked whether respondents have ever had sexual intercourse and, if so, how many partners they have had sex with in the past 12 months. For the variable indicating recent sexual experience, we coded all respondents who stated they had had at least one partner in the last year as one. We coded all other respondents, including those who had never had sexual intercourse, as zero. Respondents were then asked detailed questions about their three most recent partners in the past 12 months, including whether they had used a condom the last time they had sex with each of those partners. For those who had had sex, we examined condom use for all mentioned partnerships (up to three). If a condom had not been used with one or more partners, we coded condom use at last sex as no (zero), and we coded it as yes (one) if a condom had been used at last sex for all partners mentioned. This variable thus requires a high standard of consistent condom use across partners (NIAID 2001).

Our explanatory variables of interest—experiences of school, work, and other activities - are posited to play an integral role in sexual risk-taking among adolescents. We use two analytic approaches to examine these relationships. First, employing timeuse data, we describe the activities of young people over a 24-hour period. We indicate the association between the way adolescents use their time and their risky sexual behavior. The time-use data, however, do not allow us to make causal statements about risky 
sexual behavior because of the ambiguity of causal pathways at the individual level. For example, girls may have been having sex because they were not in school, or conversely they may not be in school because they were having sex. Cross-sectional data, including time-use data, do not allow sufficient means by which to untangle these relationships. However, time-use data do describe points of opportunity — and intervention-with respect to respondents' risk-taking behavior.

In our second analytic approach, we draw theoretically from recent work on the community and family context of adolescents' risk-taking behavior as described above. We model community influences on individual behavior, controlling for individual and household characteristics. The community variables do not measure individual associations; instead they capture dynamics of the environments in which adolescents live. Educational opportunity is defined as the proportion of young people enrolled at any level of school and the proportion of people aged 20 and older who graduated from secondary school. Opportunity structures of employment are measured by three dimensions of current employment: the proportion of adolescents performing wage labor in a community, the average number of hours they work, and the (log) wages they earn per week. Aggregate work hours represent the effort and time commitment of work opportunities, whereas wages represent the value associated with that work. Extracurricular activities are examined by measuring the proportion of adolescents participating in organized activities. Participation is coded according to three main categories of activity: sports, religious clubs, and community/youth programs, selected on the basis of frequency of participation (more than 15 percent of the sample participating in any given category). These categories closely resemble those relevant to South African young people as specified by Campbell et al. (2002). Our data do not permit an assessment of process variables, such as interactions among neighbors, at the community level; nevertheless, structural components are an important first step. We aggregate individual-level data to the cluster (or enumeration area) level, excluding the observation of the index child. ${ }^{3} \mathrm{We}$ also exclude enumeration areas containing fewer than ten observations from the analysis (less than 2 percent of the individual sample, which represents 14 of the 113 enumeration areas). Although the clusters were based on 1996 South African census boundaries to facilitate sample design and may not correspond precisely to local conceptions 
of communities, nonetheless a fairly strong sense of neighborhood exists in urban areas of Durban, and of community in village or farming areas in rural KwaZulu-Natal. Household factors are also likely to affect adolescent behaviors (Mullan Harris et al. 2001), and these influences must be controlled in model estimation. Two variables were means to this control in this analysis. The first was household type, which is used as a proxy for the economic well-being of the household. The second captures education in the household, because the value placed on schooling and the resources a household provides for it may be an important factor in determining an individual's behavior. We employ education as a dummy variable, indicating whether any adult aged 23 or older has completed at least 12 years of schooling. In addition to community and household variables, individual demographic controls of race, sex, and age are included. ${ }^{4}$

The data are described in Table 1 . They are weighted and exclude missing cases and coloured - those of mixed African and white heritage-(because the numbers are too small for meaningful analysis), bringing the total sample size to 2,992. Approximately 47 percent of the sample reported having had sexual intercourse within the last 12 months. Of those, about 47 percent had used a condom at last sex. ${ }^{5}$ About 55 percent of the sample is female, and the racial composition approximates the distribution for the sampled areas. Slightly more than 50 percent of the sample are between the ages of 16 and 19, and the other half is about evenly distributed between the younger ages (14 to 15 ) and the older ages (20 to 22). Almost 60 percent of the sample live in permanent homes, and about half reside in homes where at least one adult older than themselves has completed 12 or more years of education. The individual distributions of the community variables are given in the lower panel of the table. About 70 percent of young people are enrolled in some form of school on average across communities, and about 10 percent work for wages for about 30 hours per week, earning on average about 200 Rand a week (about US\$30 per week in 1999). In combination, slightly more than half of adolescents aged 14 to 22 are involved in some form of organized activity, although participation in specific activities varies by sex. About 45 percent of boys are involved in sports, whereas 30 percent of girls are involved in church-related activities. Boys and girls participate in community life at about the same levels (about 16 percent). Aggregate-level means and percents are similar to those at the individual level and are not shown here. ${ }^{6}$ 
Table 1 Percentage of boys and girls aged 14 to 22, by selected variables, KwaZuluNatal, South Africa, 2001

\begin{tabular}{|c|c|c|c|c|c|c|}
\hline \multirow[b]{2}{*}{ Variable } & \multicolumn{2}{|c|}{ Male } & \multicolumn{2}{|c|}{ Female } & \multicolumn{2}{|c|}{ Total } \\
\hline & Percent & (n) & Percent & (n) & Percent & (n) \\
\hline \multicolumn{7}{|l|}{ Dependent variable } \\
\hline Had sex in last 12 months & 49 & $(1,300)$ & 46 & $(1,614)$ & 47 & $(2,914)$ \\
\hline Used condom at last sex in last 12 months & 49 & (613) & 46 & (705) & 47 & $(1,318)$ \\
\hline \multicolumn{7}{|l|}{ Number of current partners } \\
\hline 0 & 55 & & 58 & & 57 & \\
\hline 1 & 27 & & 40 & & 34 & \\
\hline \multirow[t]{2}{*}{$2+$} & 18 & & 2 & & 9 & \\
\hline & & $(1,302)$ & & $(1,608)$ & & $(2,910)$ \\
\hline \multicolumn{7}{|l|}{ Independent variable } \\
\hline \multicolumn{7}{|l|}{ Race } \\
\hline African rural & 24 & & 24 & & 24 & \\
\hline African urban & 54 & & 58 & & 56 & \\
\hline Indian & 14 & & 13 & & 14 & \\
\hline \multirow[t]{2}{*}{ White } & 8 & & 5 & & 6 & \\
\hline & & $(1,346)$ & & $(1,646)$ & & $(2,992)$ \\
\hline \multicolumn{7}{|l|}{ Age } \\
\hline $14-15$ & 25 & & 25 & & 25 & \\
\hline $16-19$ & 52 & & 50 & & 51 & \\
\hline \multirow[t]{2}{*}{$20-22$} & 24 & & 25 & & 25 & \\
\hline & & $(1,346)$ & & $(1,646)$ & & $(2,992)$ \\
\hline \multicolumn{7}{|l|}{ Housing type } \\
\hline Traditional material & 19 & & 19 & & 19 & \\
\hline Temporary shack & 5 & & 5 & & 5 & \\
\hline Permanent shack & 18 & & 19 & & 19 & \\
\hline \multirow[t]{2}{*}{ Permanent house } & 58 & & 57 & & 58 & \\
\hline & & $(1,322)$ & & $(1,623)$ & & $(2,945)$ \\
\hline \multicolumn{7}{|l|}{ Education (household) } \\
\hline Adult schooling (12 $\geq$ years) & 49 & $(1,346)$ & 46 & $(1,646)$ & 47 & $(2,992)$ \\
\hline \multicolumn{7}{|c|}{ Community independent variable (not aggregated) } \\
\hline \multicolumn{7}{|c|}{ Education (individual) } \\
\hline Enrolled in primary or secondary school & 72 & $(1,340)$ & 66 & $(1,638)$ & 69 & $(2,978)$ \\
\hline Matriculated (age $\geq 20$ ) & 15 & (448) & 22 & $(568)$ & 19 & $(1,016)$ \\
\hline \multicolumn{7}{|l|}{ Work and employment } \\
\hline Currently working & 14 & $(1,346)$ & 8 & $(1,646)$ & 10 & $(2,992)$ \\
\hline Hours worked per week (mean) & 28 & $(270)$ & 33 & $(242)$ & 30 & $(512)$ \\
\hline Amount earned per week (mean, in Rand) & d) 261 & $(266)$ & 208 & $(243)$ & 238 & $(509)$ \\
\hline \multicolumn{7}{|l|}{ Organized activity } \\
\hline Community & 18 & $(1,346)$ & 15 & $(1,646)$ & 16 & $(2,992)$ \\
\hline Sports & 45 & $(1,346)$ & 17 & $(1,646)$ & 30 & $(2,992)$ \\
\hline Religious & 24 & $(1,340)$ & 31 & $(1,650)$ & 28 & $(2,990)$ \\
\hline
\end{tabular}




\section{RESULTS}

\section{Time Use among Adolescents}

Turning to the time-use data, we review the pattern and structure of the daily activities of adolescents. Because of the likely differences in time use by race and sex in South Africa, we present the data accordingly. Figure 1 shows 24-hour time use for adolescents in the study. These pie charts are based on all interviews, which took place seven days a week. Days of the week were weighted to reflect their occurrence during the interview period. Because the pie charts are aggregated over the days of the week, they approximate an "average" week of activity for adolescents. No substantial differences were found between African urban and rural distributions, so their reports are combined in the time-use analysis.

Comparisons across the pie charts show that for all races and both sexes, adolescents spend nearly 11 hours each day sleeping, eating, and attending to personal hygiene. Some striking differences appear by race, and especially by sex, however. Both African and Indian females spend about twice as much time as their male counterparts performing unpaid work. In contrast, white females spend slightly less time than white males at unpaid work, but they also devote less time to studying. Indians study more than Africans (a percentage that includes all study-related time such as travel, classroom time, and homework), but in about equal proportions by sex. The results for paid activities reflect sex and racial disparities across South Africa and the scarcity of employment opportunities. White boys report the highest proportion of time at paid work (5 percent), whereas African girls average only 1 percent of their time at paid work. African and Indian boys spend the most time hanging out -12 percent and 9 percent, respectively - a proportion that includes reports of doing nothing, hanging out at the mall or street corner, or going to bars or parties (all generally unsupervised and unstructured activities). The category "organized activities" represents adolescents' participation in sports, music, church groups, and other programs or clubs-those activities that generally are supervised. African and Indian males report the highest proportion of time spent in organized activities (6 percent). In contrast, girls report little hanging out time (7 percent or less), and relatively low levels of participation in organized activities, 4 percent or less. 
Figure 1 24-hour time use among adolescents surveyed, by race and sex, KwaZuluNatal, South Africa, 2001

African boys

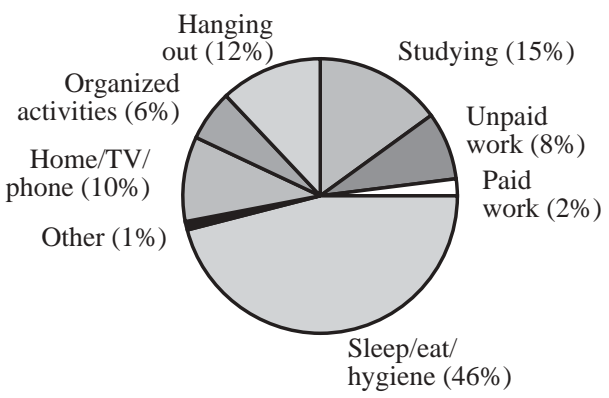

Indian boys

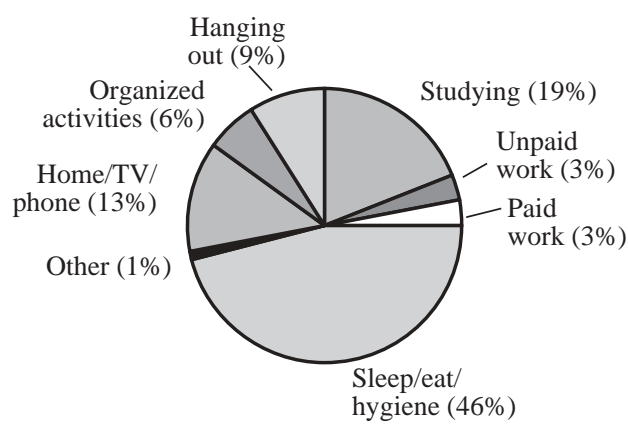

White boys

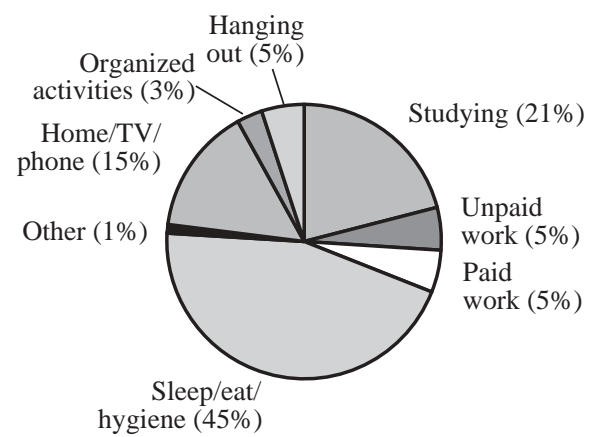

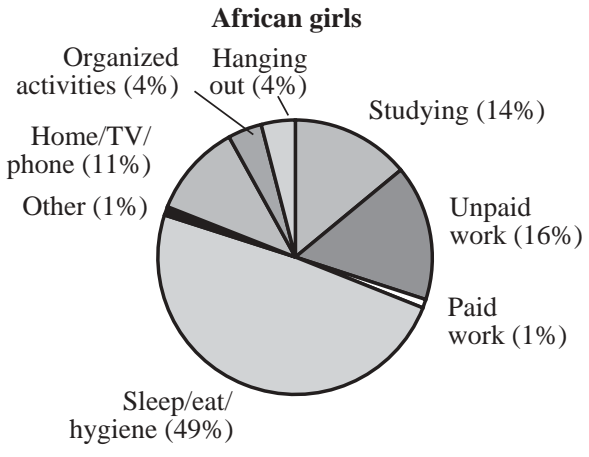

Indian girls

Organized Hanging activities (2\%) out $(5 \%)$

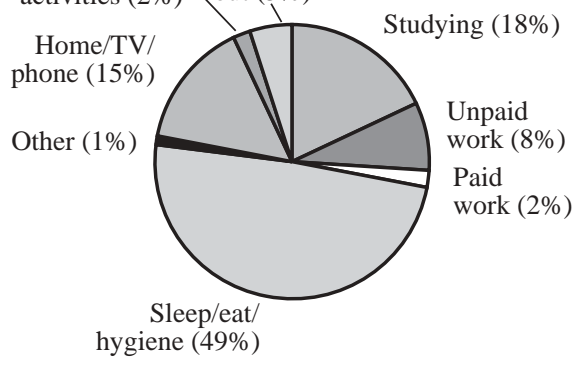

White girls

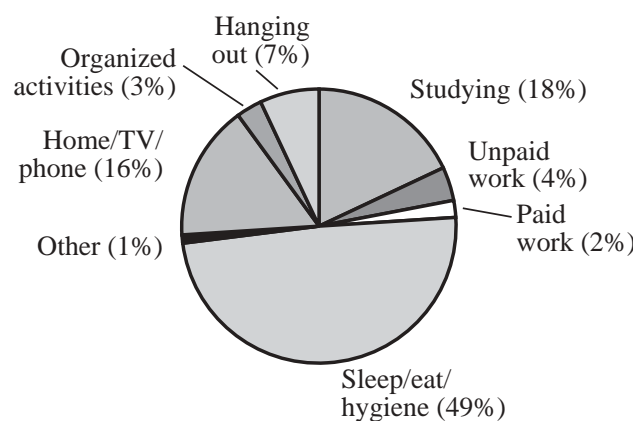


Is this differential pattern of time use associated with risky behavior? As noted above, analysis of time use at the bivariate level is subject to precautions similar to other types of modeling because no causal inferences can be made. Nevertheless, the associations we found are revealing. To simplify the analysis, we focused on two time-use indicators that are readily influenced by programs and policies: hanging out and organized activities. Also for simplicity, we chose only two of the dependent variables: had sex within the last year and, if so, used a condom. Figure 2 shows the patterns of association for hanging out by race and sex in units of hours instead of percentages of time. For most groups, the number of hours spent hanging out is positively associated with having had sex in the last year and negatively associated with condom use. Only among African boys $(p=0.000)$ and girls $(p=0.000)$ and Indian boys $(p=0.031)$ is a significant relationship found between hours spent hanging out and having had sex in the last

Figure 2 Adolescents' reports of hours spent hanging out, by sexual behavior and condom use, KwaZulu-Natal, South Africa, 2001

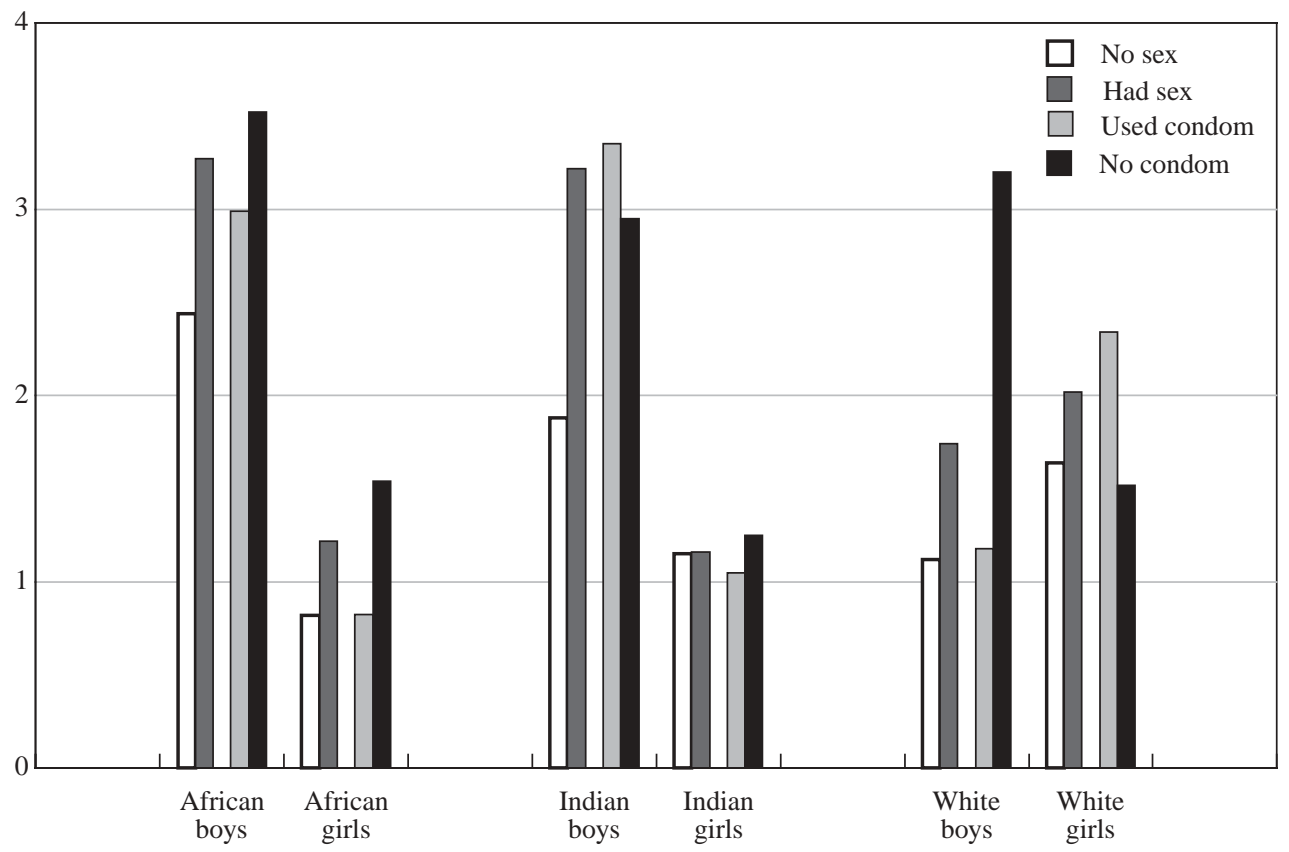


12 months. The number of hours spent hanging out was not found to be significantly related to condom use for any group.

The converse of hanging out is participation in planned activities, shown in Figure 3. Again, the associations generally act in the expected direction for having had sex recently, although no significant relationship was found for African girls or for Indian boys or girls. Participation in organized activities is not consistently associated with condom use by race or sex. Among African boys and Indian boys and girls, activities were not related to condom use, whereas among white girls the number of hours spent in organized activities was associated with not using a condom ( $p$ $=0.000$ ). A positive and significant relationship was found between hours spent in organized activities and condom use for African boys $(p=0.002)$ and white boys $(\mathrm{p}=0.000)$.

Figure 3 Adolescents' reports of hours spent in organized activities, by sexual behavior and condom use, KwaZulu-Natal, South Africa, 2001

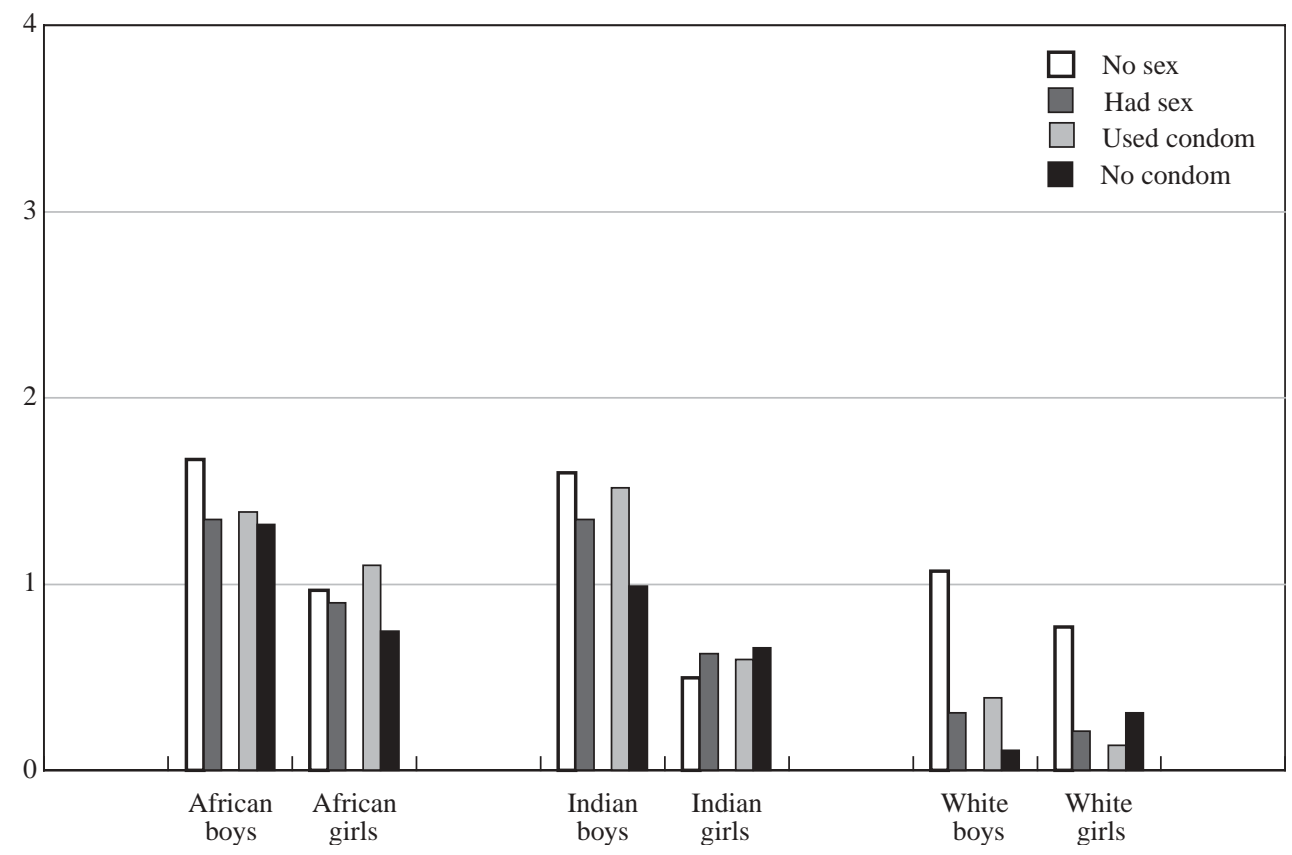


The analysis for these two categories of time use suggest that opportunities—or the lack of them-- are likely to have an influence on adolescents' sexual behavior. The influence is not a simple one because the pattern of relationships varies across groups. The time-use analysis is intended as descriptive and exploratory. Programs or policies will influence adolescents' behavior only to the extent that they make sense in the context of young people's lives.

\section{Community Influences on Adolescents' Sexual Behavior}

Because of the difference by sex in time use and risk-taking, separate models are presented for girls and boys. A nested-model approach is used to demonstrate the changes in effects when community-level education, work, and activity variables are added. All models are based on weighted data, and standard errors are adjusted for cluster design of the sample. Odds ratios and p-values are shown in all tables.

Table 2 presents the results for the probability of girls' having had sex in the past 12 months. Model 1 indicates that white girls are about three times more likely than Indian girls to have had sex in the last 12 months, and although the odds ratio is sizeable for urban African girls, the effect is barely statistically significant. As expected, the probability of girls' having had sex increases substantially with age. No effect of housing type is found, but education of the household is significantly and negatively related to the likelihood of having had sex. When the community-level education variables are included (see Model 2), however, the effects of household education are weakened. Also, African urban girls are more than two times more likely to have had sex than white girls $(\mathrm{p}=0.03)$. Girls appear to be influenced by the opportunities available in their communities, even after controlling for individual and household characteristics. The effect of both community-level education variables on the probability of girls' having had sex in the last year is highly significant and highly negative. Community-level wages and participation in sports programs also appear to make a difference. Those girls who live in communities in which young people make more money working are about onethird less likely to have had sex within the last 12 months than are those who live elsewhere. Similarly, those who live in communities where participation in sports is high are only one-fifth as likely to have had sex in the past year as are those who live in communities where participation in sports is low. 
Table 2 Odds ratios for adolescent girls surveyed who reported having had sex in the last 12 months, KwaZulu-Natal, South Africa, 2001

\begin{tabular}{|c|c|c|c|c|}
\hline \multirow[b]{2}{*}{ Characteristic } & \multicolumn{2}{|c|}{ Model 1} & \multicolumn{2}{|c|}{ Model 2} \\
\hline & Odds ratio & p-value & Odds ratio & p-value \\
\hline \multicolumn{5}{|l|}{ Race } \\
\hline White (r) & 1.00 & - & 1.00 & - \\
\hline Indian & 0.30 & 0.018 & 0.42 & 0.069 \\
\hline African rural & 1.70 & 0.273 & 2.22 & 0.067 \\
\hline African urban & 2.41 & 0.052 & 2.24 & 0.033 \\
\hline \multicolumn{5}{|l|}{ Age } \\
\hline $14-15(r)$ & 1.00 & - & 1.00 & - \\
\hline $16-19$ & 11.60 & 0.000 & 12.20 & 0.000 \\
\hline 20-22 & 55.12 & 0.000 & 60.93 & 0.000 \\
\hline \multicolumn{5}{|l|}{ Housing type } \\
\hline Permanent house (r) & 1.00 & - & 1.00 & - \\
\hline Traditional material & 0.81 & 0.504 & 0.72 & 0.310 \\
\hline Temporary shack & 2.02 & 0.166 & 1.45 & 0.547 \\
\hline Permanent shack & 0.94 & 0.850 & 0.73 & 0.372 \\
\hline \multicolumn{5}{|l|}{ Education (household) } \\
\hline Adult schooling (12 $\geq$ years) & 0.57 & 0.033 & 0.59 & 0.065 \\
\hline \multicolumn{5}{|l|}{ Education (aggregate) } \\
\hline Enrolled in primary or secondary school & - & - & 0.05 & 0.005 \\
\hline Matriculated (age $\geq 20$ ) & - & - & 0.01 & 0.004 \\
\hline \multicolumn{5}{|l|}{ Work (aggregate) } \\
\hline Currently working & - & - & 0.88 & 0.755 \\
\hline Average earnings per week (log) & - & - & 0.68 & 0.009 \\
\hline Average hours per week & - & - & 1.00 & 0.628 \\
\hline \multicolumn{5}{|l|}{ Organized activity } \\
\hline Community & - & - & 4.83 & 0.115 \\
\hline Sports & - & - & 0.19 & 0.024 \\
\hline Religious & - & - & 0.59 & 0.524 \\
\hline (n) & \multicolumn{2}{|c|}{$(1,595)$} & \multicolumn{2}{|c|}{$(1,558)$} \\
\hline Wald chi-squared & 456.0 & 610.7 & & \\
\hline
\end{tabular}

$(\mathrm{r})=$ Reference category. $\quad-=$ Not applicable.

The analogous models for boys, shown in Table 3, indicate a different pattern of effects. African boys from urban areas are significantly more likely (anywhere from 2.6 to 3.1 times more likely) to have had sex in the last year than white boys, a finding that persists after community variables are included. As it is for girls, age for boys is highly and positively related to having had sex; neither household-level characteristic is significant, however. Although community-level effects in the girls' model were very important, not one measure of community influence is significant for boys. 
Table 3 Odds ratios for adolescent boys surveyed who reported having had sex in the last 12 months, KwaZulu-Natal, South Africa, 2001

\begin{tabular}{|c|c|c|c|c|}
\hline \multirow[b]{2}{*}{ Characteristic } & \multicolumn{2}{|c|}{ Model 1} & \multicolumn{2}{|c|}{ Model 2} \\
\hline & Odds ratio & p-value & Odds ratio & p-value \\
\hline \multicolumn{5}{|l|}{ Race } \\
\hline White (r) & 1.00 & - & 1.00 & - \\
\hline Indian & 0.66 & 0.395 & 0.58 & 0.311 \\
\hline African rural & 2.83 & 0.058 & 2.89 & 0.070 \\
\hline African urban & 2.55 & 0.038 & 3.08 & 0.016 \\
\hline \multicolumn{5}{|l|}{ Age } \\
\hline $14-15(\mathrm{r})$ & 1.00 & - & 1.00 & - \\
\hline $16-19$ & 11.37 & 0.000 & 12.48 & 0.000 \\
\hline 20-22 & 42.34 & 0.000 & 45.97 & 0.000 \\
\hline \multicolumn{5}{|l|}{ Housing type } \\
\hline Permanent house (r) & 1.00 & - & 1.00 & - \\
\hline Traditional material & 0.73 & 0.375 & 0.61 & 0.153 \\
\hline Temporary shack & 2.73 & 0.161 & 2.51 & 0.194 \\
\hline Permanent shack & 0.89 & 0.788 & 0.82 & 0.643 \\
\hline \multicolumn{5}{|l|}{ Education (household) } \\
\hline Adult schooling (12 $\geq$ years) & 1.14 & 0.511 & 1.29 & 0.266 \\
\hline \multicolumn{5}{|l|}{ Education (aggregate) } \\
\hline Enrolled in primary or secondary school & - & - & 0.32 & 0.293 \\
\hline Matriculated (age $\geq 20$ ) & - & - & 1.00 & 0.999 \\
\hline \multicolumn{5}{|l|}{ Work (aggregate) } \\
\hline Currently working & - & - & 0.59 & 0.184 \\
\hline Average earnings per week $(\log )$ & - & - & 0.75 & 0.080 \\
\hline Average hours per week & - & - & 1.01 & 0.293 \\
\hline \multicolumn{5}{|l|}{ Organized activity } \\
\hline Community & - & - & 0.63 & 0.570 \\
\hline Sports & - & - & 3.08 & 0.208 \\
\hline Religious & - & - & 1.84 & 0.445 \\
\hline (n) & \multicolumn{2}{|c|}{$(1,272)$} & \multicolumn{2}{|c|}{$(1,242)$} \\
\hline Wald chi-squared & 369.8 & 603.0 & & \\
\hline
\end{tabular}

$(\mathrm{r})=$ Reference category. $\quad-=$ Not applicable.

Tables 4 and 5 present the results of the logit analysis for condom use for girls and boys. Strikingly, no significant racial differences are found in any model, nor do any age differences appear for girls or boys: Even after controlling for individual and household characteristics and community influences, neither age nor race makes a difference in condom use at last sex. For girls, those living in houses made of traditional materials 
Table 4 Odds ratios for adolescent girls surveyed who reported having used condoms during last intercourse in the last 12 months, KwaZulu-Natal, South Africa, 2001

\begin{tabular}{|c|c|c|c|c|}
\hline \multirow[b]{2}{*}{ Characteristic } & \multicolumn{2}{|c|}{ Model 1} & \multicolumn{2}{|c|}{ Model 2} \\
\hline & Odds ratio & p-value & Odds ratio & p-value \\
\hline \multicolumn{5}{|l|}{$\overline{\text { Race }}$} \\
\hline White (r) & 1.00 & - & 1.00 & - \\
\hline Indian & 0.71 & 0.549 & 0.75 & 0.638 \\
\hline African rural & 0.85 & 0.765 & 0.73 & 0.604 \\
\hline African urban & 0.70 & 0.430 & 0.52 & 0.172 \\
\hline \multicolumn{5}{|l|}{ Age } \\
\hline $14-15(r)$ & 1.00 & - & 1.00 & - \\
\hline $16-19$ & 0.96 & 0.933 & 0.81 & 0.645 \\
\hline 20-22 & 0.98 & 0.967 & 0.83 & 0.660 \\
\hline \multicolumn{5}{|l|}{ Housing type } \\
\hline Permanent house (r) & 1.00 & - & 1.00 & - \\
\hline Traditional material & 0.48 & 0.012 & 0.58 & 0.032 \\
\hline Temporary shack & 0.37 & 0.297 & 0.44 & 0.457 \\
\hline Permanent shack & 0.70 & 0.138 & 1.01 & 0.970 \\
\hline \multicolumn{5}{|l|}{ Education (household) } \\
\hline Adult schooling ( $12 \geq$ years $)$ & 1.61 & 0.004 & 1.38 & 0.067 \\
\hline \multicolumn{5}{|l|}{ Education (aggregate) } \\
\hline Enrolled in primary or secondary school & - & - & 2.54 & 0.406 \\
\hline Matriculated (age $\geq 20$ ) & - & - & 2.02 & 0.784 \\
\hline \multicolumn{5}{|l|}{ Work (aggregate) } \\
\hline Currently working & - & - & 2.40 & 0.028 \\
\hline Average earnings per week (log) & - & - & 1.42 & 0.009 \\
\hline Average hours per week & - & - & 0.99 & 0.183 \\
\hline \multicolumn{5}{|l|}{ Organized activity } \\
\hline Community & - & - & 0.96 & 0.966 \\
\hline Sports & - & - & 0.23 & 0.069 \\
\hline Religious & - & - & 0.44 & 0.202 \\
\hline (n) & \multicolumn{2}{|c|}{ (693) } & \multicolumn{2}{|c|}{$(677)$} \\
\hline Wald chi-squared & \multicolumn{2}{|c|}{38.7} & \multicolumn{2}{|c|}{79.9} \\
\hline
\end{tabular}

(r) = Reference category. $\quad-=$ Not applicable.

are significantly less likely to use a condom than are those living in permanent houses, although the effect is reduced once community measures are included. Although household-level education is important for girls, that effect is also diminished once community variables are considered. In contrast with the model for having had sex, however, only community-level economic variables are important for girls' use of condoms at last 
Table 5 Odds ratios for adolescent boys surveyed who reported having used condoms during last intercourse in the last 12 months, KwaZulu-Natal, South Africa, 2001

\begin{tabular}{|c|c|c|c|c|}
\hline \multirow[b]{2}{*}{ Characteristic } & \multicolumn{2}{|c|}{ Model 1} & \multicolumn{2}{|c|}{ Model 2} \\
\hline & Odds ratio & p-value & Odds ratio & p-value \\
\hline \multicolumn{5}{|l|}{ Race } \\
\hline White (r) & 1.00 & - & 1.00 & - \\
\hline Indian & 1.06 & 0.931 & 1.30 & 0.697 \\
\hline African rural & 0.37 & 0.138 & 0.34 & 0.164 \\
\hline African urban & 0.55 & 0.362 & 0.43 & 0.288 \\
\hline \multicolumn{5}{|l|}{ Age } \\
\hline $14-15(r)$ & 1.00 & - & 1.00 & - \\
\hline $16-19$ & 0.83 & 0.652 & 0.77 & 0.541 \\
\hline $20-22$ & 0.79 & 0.673 & 0.64 & 0.446 \\
\hline \multicolumn{5}{|l|}{ Housing type } \\
\hline Permanent house (r) & 1.00 & - & 1.00 & - \\
\hline Traditional material & 0.82 & 0.533 & 0.90 & 0.707 \\
\hline Temporary shack & 0.82 & 0.391 & 0.74 & 0.221 \\
\hline Permanent shack & 1.16 & 0.670 & 1.33 & 0.390 \\
\hline \multicolumn{5}{|l|}{ Education (household) } \\
\hline Adult schooling (12 $\geq$ years) & 2.04 & 0.000 & 1.96 & 0.000 \\
\hline \multicolumn{5}{|l|}{ Education (aggregate) } \\
\hline Enrolled in primary or secondary school & - & - & 0.05 & 0.002 \\
\hline Matriculated (age $\geq 20$ ) & - & - & 0.01 & 0.035 \\
\hline \multicolumn{5}{|l|}{ Work (aggregate) } \\
\hline Currently working & - & - & 0.28 & 0.056 \\
\hline Average earnings per week $(\log )$ & - & - & 1.48 & 0.029 \\
\hline Average hours per week & - & - & 0.99 & 0.058 \\
\hline \multicolumn{5}{|l|}{ Activities } \\
\hline Community & - & - & 1.69 & 0.554 \\
\hline Sports & - & - & 0.11 & 0.005 \\
\hline Religious & - & - & 0.58 & 0.579 \\
\hline (n) & \multicolumn{2}{|c|}{$(604)$} & \multicolumn{2}{|c|}{$(589)$} \\
\hline Wald chi-squared & \multicolumn{2}{|c|}{36.5} & \multicolumn{2}{|c|}{88.3} \\
\hline
\end{tabular}

(r) = Reference category. $\quad-=$ Not applicable.

sex. The proportion currently working and average earnings per week at the level of the community both have a significant and positive effect. Girls who live in communities where more young people are working for wages are almost two and a half times more likely to report having used a condom than are those living in communities where fewer adolescents are working. Those who live in areas where adolescents earn relatively higher 
wages are about 40 percent more likely to use a condom than are those from communities where wages are lower. No significant effect of community-level organized activities on condom use is found.

As shown in Table 5, condom use for boys, as noted above, is not related to race or age. Household-level education is significantly related, however. Even after controlling for community factors, boys in households where someone has attained 12 or more years of education are almost two times more likely to use a condom at last sex than are boys in households where this is not the case. Education at the community level is significantly and negatively associated with boys' likelihood of having used condoms, however. Like the model estimated for girls, community-level wages are significantly and positively associated with condom use. Boys from higher-wage communities are about 50 percent more likely to report having used a condom than are those from lower-wage areas. Interestingly, effects for the other two measures of community economic wellbeing, proportion working and hours worked per week, are in the opposite direction and marginally not significant at the 0.05 level. Finally, only level of participation in sports has an effect on boys' condom use, but in the opposite direction of expectation; boys in areas of high participation are only about one-tenth as likely to report having used a condom as are boys from low-participation areas.

In sum, our findings show that at the community level, educational, employment, and organized-activity opportunities are important influences on individual sexual risktaking, but not always in expected directions. Educational opportunities in the community tend to decrease odds of sexual activity for girls; for boys, they tend to decrease the odds of condom use. Employment opportunities at the community level tend to decrease girls' sexual activity and to increase condom use for both boys and girls. The average amount of earnings per week, one of the measures of employment opportunities, appears to exert a particularly powerful influence on the behavior of both boys and girls. Although this finding could suggest a relationship between cost of condoms and use, condoms are freely accessible throughout the communities involved in this study. More likely, young people may observe the amount of earnings available to them in their communities; those who perceive the potential for a high level of pay may be more inclined to engage in safe-sex practices than those who perceive a low potential. Finally, 
regarding adolescents' community-level participation in organized activities, only level of participation in sports seems to matter; no effect was found for either community groups or religious groups for either sex or for either behavior considered. Communitylevel participation in sports was found to decrease the probability of condom use among boys, but it also decreased the risk among girls of having had sex in the last year.

\section{DISCUSSION, CONCERNS, AND IMPLICATIONS}

Results of this study indicate that in addition to individual and household characteristics such as age, sex, race, and household socioeconomic status, community variables representing structures of opportunities for adolescents make a difference in the sexual behavior of young people in South Africa. By shedding light on the often shrouded sexual decisions and risks taken by adolescents, these findings could help identify promising interventions and highlight likely policy pitfalls. One of the key findings indicates that one's sex is far more important than race in predicting sexual risk-taking among young people. For both sexes, slight racial differences appear for having had sex in the last year. No discernible differences are found for condom use by race in any of the models for boys or girls, however. In South Africa, stereotypes of each race persist and are harmful in terms of intervention, program design, and target group. Persistent stereotypes are also harmful to those individuals who believe they are not at risk because of a group affiliation.

Sex is also critical with respect to the effects of education on sexual behavior. Girls living in areas with a high level of opportunity for educational attainment tend not to report having had sex recently, whereas no detectable effect on this behavior for boys is found for this variable. Yet, the same situation is associated with a lower likelihood of condom use for boys, even while the effects of household-level education act in the expected direction: Boys from households with a better-educated adult are more likely to report having used a condom. These results suggest that formal education has not yet produced an environment where girls and boys elect to use condoms. Education is clearly an important factor for both boys and girls, however, if not at the community level, then at the household level. Indeed, the contradictory results for girls and boys suggest that the educational environment may manifest itself differently for girls in various aspects of their sexual behavior. Our findings suggest that schools have ample latitude to pro- 
mote the knowledge, understanding, and skills to enable young people to make responsible decisions about their sexual behavior. They also suggest that educational effects may persist after school is completed, because the educational levels of other household members are found to have an important association with risky behavior.

In addition to education, employment prospects shape young people's future plans and expectations. Current economic opportunities for South African adolescents are greatly limited, but the promise of landing a potentially lucrative job appears to influence behavior. Earning potential asserted a strong negative influence on having had sex within the past year among girls and a consistently positive effect on condom use among both boys and girls. The results of this study suggest that if young people perceive that it is possible to work for reasonable wages, they are more likely to engage in safer sex practices. In short, perceived high-earnings potential may be a key antidote to the fatalism of adolescents recorded in other research and in media reports in South Africa. Our results suggest that programs focusing on livelihoods for both boys and girls could be important in bringing about safer sex practices (Steele et al. 1998). Several projects have begun to address issues of adolescents' time and skills; few of these programs consider a link between livelihoods and sexual behavior, however (Esim et al. 1999; Segil and Sebastiani 1999).

The impact of participation in organized activities was found to be ambiguous. This study provides evidence that high levels of participation in sports for adolescents decreases girls' likelihood of having sex, for example. In contrast, for boys, the level of participation decreases the likelihood of using condoms at last sex. These results suggest that organized activities, especially sports, may be a critical point of intervention, albeit in different ways for each sex. Girls may respond favorably to the possibility of sports participation, especially if their peers already participate (see, for example, Brady 1998). For boys, participating in sports or having opportunities for participation may actually increase opportunities for sex and may enhance the perception that "real men" don't use condoms. Different messages tailored to each sex by means of sports events may be effective paths for intervention.

Although the results of this study provide promising programmatic direction, they require some qualification. This study, like others similar to it, does not consider 
the causal mechanisms between time use and sexual risk-taking. Do adolescents desist or refrain from risky behavior because of what they learn on the job, at school, or in a club? Or do they gain important negotiating skills through participation in these activities? Or do they garner sufficient self-esteem and confidence to seek out and maintain healthy relationships? What are the influences of peers in each of these settings? Untangling these mechanisms will provide information important for appropriate program design focused on adolescents.

Strong theoretical arguments and a small but growing body of empirical research suggest that community conditions are important in the lives—and decisionmaking — of adolescents. Their susceptibility to outside forces may prove to be both a blessing and a curse. If they perceive that high returns accrue from educational attainment and employment options, they may be motivated to engage in safer sex practices. If they are unable to stay in school or to find jobs, however, they may discount the costs of acquiring HIV or other sexually transmitted diseases and, thus, be willing to take greater risks. The results of this study should encourage researchers studying HIV/AIDS, particularly in high-prevalence settings such as South Africa, to consider a wide range of influences on adolescent lives because the context in which adolescents face decisions may be critical to their sexual decisionmaking.

\section{Notes}

1 Although community influences have not been featured in the literature, a few recent articles assess the effects of community behavioral interventions (Agha et al. 2001; Ahmed et al. 2001). These tend to describe community context or controls in relation to the behavioral intervention.

2 Gage (1998), in a review of sexual decisionmaking among adolescents in subSaharan Africa, asserts that in some cases, nondecisionmaking is operative. To reflect this possibility, we also modeled this set of behaviors as a multinomial logit, so that no temporal ordering is assumed, and the substantive conclusions of our study were similar to Gage's.

3 Because samples are limited in several of the enumeration areas, the aggregate community variables are not calculated separately by sex or race. We contend, 
however, that in postapartheid South Africa, differences in opportunities for educational attainment, employment, and participation in organized activities are minimal within a given neighborhood. Moreover, most of the work opportunities for adolescents are not sex-differentiated by wage, hours, or type. Although boys may be more likely to engage in construction work and girls may be more likely to serve as hairdressers, for example, in a consideration of the community as a whole, such differences are unlikely to affect adolescents' participation in risky sexual behavior.

4 Because of the endogenous relationship of a given adolescent's own work or education with the outcome of interest, we did not include these in the multivariate analyses.

5 The relatively high level of condom use may seem contrary to expectations. Reports from several other settings in the region indicate low levels of condom use among young people. Unfortunately, empirical data on this topic is limited for South Africa. Studies tend to be localized and qualitative in nature. A few exceptions are found, although direct comparisons are difficult because of differences in samples or questions. The South African DHS (1998) reports that among girls aged 15 to 19, 20 percent used a condom at last sex. In 1996, Richter reported that among her sample of 864 urban African adolescents (girls and boys aged 16 to 20), condom use at last sex was 27 percent. Compared with these figures, ours are comparatively high. Recent media reports, however, suggest that safe-sex practices are increasing (Reuters 2001), as demonstrated by data from antenatal clinics showing stabilized rates of new infection (Makubalo et al. 2000) and by views expressed in focus-group discussions with adolescents, in which young people who do not use condoms are described as "ignorant." Indeed, our study also found remarkably favorable attitudes toward condom use among a wide range of adolescents (Robinson et al. 2001).

6 Aggregate values for an enumeration area vary for each adolescent because each adolescent contributes a different value to the aggregate that is then excluded for the specific aggregation valuation for that index child. 


\section{References}

Agha, S., A. Karlyn, and Dominique Meekers. 2001. "The promotion of condom use in non-regular sexual partnerships in urban Mozambique," Health Policy and Planning 16(2): 144-151.

Ahmed, S., T. Lutalo, M. Wawer, D. Serwadda, and N.K. Sewankambo. 2001. "HIV incidence and sexually transmitted disease prevalence associated with condom use: A population study in Rakai, Uganda,” AIDS 15(16): 2171-2179.

Ajayi, Ayorinde A., Leah T. Marangu, Janice Miller, and John M. Paxman. 1991. “Adolescent sexuality and fertility in Kenya: A survey of knowledge, perceptions, and practices," Studies in Family Planning 22(4): 205-216.

Ali, M.M. 2001. "Quality of care and contraceptive pill discontinuation in rural Egypt," Journal of Biosocial Science 33(2): 161-172.

Amin, Sajeda, Ian Diamond, Ruchira T. Naved, and Margaret Newby. 1998. "Transition to adulthood of female garment workers in Bangladesh," Studies in Family Planning 29(2): 185-200.

Billy, J.O.G., Karin L. Brewster, and W.R. Grady. 1994. "Contextual effects on the sexual behavior of adolescent women," Journal of Marriage and the Family 56(2): 387404.

Blanc, Ann and Ann Way. 1998. "Sexual behavior and contraceptive knowledge and use among adolescents in developing countries," Studies in Family Planning 29(2): 106-116.

Boyer, C. and S. Kegeles. 1991. "AIDS risk and prevention among adolescents," Social Science \& Medicine 33(1): 11-23.

Brady, Martha. 1998. "Laying the foundation for girls' healthy futures: Can sports play a role?" Studies in Family Planning 29(1): 79-82.

Brewster, Karin L. 1994. "Neighborhood context and the transition in sexual activity among young black women," Demography 31(4): 603-614.

Brooks-Gunn, Jeanne, Greg J. Duncan, and J. Lawrence Aber (eds.). 1997. Neighborhood Poverty: Context and Consequences for Children. Volume I. New York: Russell Sage Foundation. 
Campbell, C., B. Williams, and D. Gilgen. 2002. "Is social capital a useful conceptual tool for exploring community-level influences on HIV infection? An exploratory case study from South Africa," AIDS Care 14(1): 41-54.

Casterline, John B. 1982. "Community Effects on Individual Demographic Behavior: Multilevel Analysis of WFS Data," World Fertility Survey Technical Report No. 1816. Voorburg: International Statistical Institute.

(ed.). 1985. The Collection and Analysis of Community Data. Voorburg: International Statistical Institute.

Cates, Willard Jr. 2001. "The NIH Condom Report: The glass is 90\% full," Family Planning Perspectives 33(5): 231-233.

Central Statistical Service. 1997. South African Census 1996: Preliminary Estimates of the Size of the Population of South Africa. Pretoria: Central Statistical Service.

Coleman, J.S. 1988. "Social capital in the creation of human capital," American Journal of Sociology 94 (Supplement): S95-S120.

Curtis, Siân L. and Fiona Steele. 1996. "Variations in familial neonatal mortality risks in four countries,” Journal of Biosocial Science 28(2): 141-159.

Darling, Nancy and Laurence Steinberg. 1997. "Community influences on adolescent achievement and deviance," in Neighborhood Poverty: Policy Implications in Studying Neighborhoods. Volume II. Eds. Jeanne Brooks-Gunn, Greg J. Duncan, and J. Lawrence Aber. New York: Russell Sage.

DeGraff, Deborah S., R.E. Bilsborrow, and David K. Guilkey. 1997. "Community-level determinants of contraceptive use in the Philippines: A structural analysis," Demography 33(3): 385-398.

Duncan, Greg J., James P. Connell, and Pamela K. Klebanov. 1997. "Conceptual and methodological issues in estimating causal effects of neighborhoods and family conditions on individual development," in Neighborhood Poverty: Context and Consequences for Children. Volume I. Eds. Jeanne Brooks-Gunn, Greg J. Duncan, and J. Lawrence Aber. New York: Russell Sage.

Entwisle, Barbara, Ronald R. Rindfuss, David K. Guilkey, A. Chamratrithirong, Sara Curran, and Y. Sawangdee. 1996. "Community and contraceptive choice in rural Thailand: A case study of Nang Rong," Demography 33(1): 1-11. 
Esim, S., N. Varia, and G. Durón. 1999. “Adolescent livelihoods: A selective review of issues and programmes," <http://www.icrw.org/adollivelihoods.html>. Accessed February 2001.

Flannery, D., L. Williams, and A. Vazsonyi. 1999. "Who are they with and what are they doing? Delinquent behavior, substance use, and early adolescents' after school time," American Journal of Orthopsychiatry 69(2): 247-253.

Frohlich, Katherine L., Louise Potvin, Patrick Chabot, and Ellen Corin. 2002. "A theoretical and empirical analysis of context: Neighbourhoods, smoking and youth," Social Science and Medicine 54: 1401-1417.

Gage, Anastasia. 1998. "Sexual activity and contraceptive use: The components of the decisionmaking process," Studies in Family Planning 29(2): 154-166.

Gephart, Martha. 1997. "Neighborhoods and communities as contexts for development," in Neighborhood Poverty: Context and Consequences for Children. Volume I. Eds. Jeanne Brooks-Gunn, Greg J. Duncan, and J. Lawrence Aber. New York: Russell Sage.

Gilbert, Leah and Liz Walker. 2002. "Treading the path of least resistance: HIV/AIDS and social inequalities: A South African case study," Social Science and Medicine 54: 1093-1110.

Gupta, Neeru. 2000. "Sexual initiation and contraceptive use among adolescent women in Northeast Brazil," Studies in Family Planning 31(3): 228-238.

Hingson, R., L. Strutin, B. Berlin, and T. Heeren. 1990. "Beliefs about AIDS, use of alcohol and drugs, and unprotected sex among Massachusetts adolescents," American Journal of Public Health 80(3): 295-299.

International Labour Organization. 1999. Child Labour Statistics: South Africa. <http:/ /www.ilo.org/public/english/standards/ipec/simpoc/southafrica/index.htm>. Accessed April 2002.

Jaccard, J., P.J. Dittus, and V.V. Gordon. 1996. "Maternal correlates of adolescent sexual and contraceptive behavior," Family Planning Perspectives 28(4): 159-165, 185.

Jemmott III, J. and S. Jemmott. 1993. "Alcohol and drug use during sexual activity: Predicting the HIV-risk-related behaviours of inner city male adolescents," Journal of Adolescent Research 8(1): 41-57. 
Kaufman, Carol E. 1998. "Contraceptive use in South Africa under apartheid," Demography 35(4): 421-434.

Kirby, Douglas. 1999. Looking for Reasons Why: The Antecedents of Adolescent Sexual Risk-taking, Pregnancy, and Childbearing. Washington, DC: National Campaign to Prevent Teen Pregnancies.

—_. 2001. "Understanding what works and what doesn't in reducing adolescent sexual risk-taking," Family Planning Perspectives 33(6): 276-281.

Ku, L., F.L. Sonenstein, L.D. Lindberg, C.H. Bradner, S. Boggess, and J.H. Pleck. 1998. "Understanding changes in sexual activity among young metropolitan men: 19791995," Family Planning Perspectives 30(6): 256-262.

Langer, L. and C. Girad. 1999. "Risky sexual behaviour among substance abusing adolescents: Assessing the effect of decision-making and avoidance motives," International Journal of Adolescence and Youth 7: 327-348.

Langer, L.M. and J.G. Tubman. 1997. “ Risky sexual behaviour among substance-abusing adolescents: Psychosocial and contextual factors," American Journal of Orthopsychiatry 67(2): 315-322.

Larson, Reed and Suman Verma. 1999. "How children and adolescents spend time across the world: Work, play and developmental opportunities," Psychological Bulletin 125(6): 701-736.

Leclerc-Madlala, S. 1997. "Infect one, infect all: Zulu youth response to the AIDS epidemic in South Africa," Medical Anthropology 17(4): 363-380.

Lloyd, Cynthia B. and Barbara S. Mensch. 1999. "Implications of formal schooling for girls' transitions to adulthood in developing countries," in Critical Perspectives on Schooling and Fertility in the Developing Countries. Eds. Caroline Bledsoe et al. Washington, DC: National Academy Press: Pp. 80-104.

Lloyd, Cynthia B., Carol E. Kaufman, and Paul Hewett. 2000. "The spread of primary schooling in sub-Saharan Africa: Implications for fertility change," Population and Development Review 26(3): 483-515.

MacPhail, C. and C. Campbell. 2001. "II think condoms are good but, aai, I hate those things': Condom use among adolescents and young people in a South African township,” Social Science and Medicine 52(11): 1613-1627. 
Magadi, M., Ian Diamond, and N. Madise. 2001. "Analysis of factors associated with maternal mortality in Kenyan hospitals," Journal of Biosocial Science 33(3): 375389.

Magnani, Robert J., Ali Mehryar Karim, Lisa A. Weiss, Katherine C. Bond, Musonda Lemba, and Gwendolyn T. Morgan. 2001. "Reproductive health risk and protective factors among youth in Lusaka, Zambia,” Journal of Adolescent Health 30(1): 76-86.

Makubalo, L.E., Jonathan Levin, and R. Mulumba. 2000. "Survey of HIV prevalence among women attending antenatal clinics in South Africa 1999," AIDS Bulletin 9(2): 9-10.

Meekers, Dominique and Ghyasuddin Ahmed. 1999. "Pregnancy-related school dropouts in Botswana," Population Studies 53(2): 195-209.

Mensch, Barbara S. and Cynthia B. Lloyd. 1998. "Gender differences in the schooling experiences of adolescents in low-income countries: The case of Kenya," Studies in Family Planning 29(2): 167-184.

Mensch, Barbara S., Judith Bruce, and Margaret E. Greene. 1998. The Uncharted Passage: Girls'Adolescence in the Developing World. New York: Population Council.

Mullan Harris, Kathleen and Suzanne Ryan. 2001. "Family processes, neighborhood context, and adolescent risk behavior," paper presented at the annual meeting of the Population Association of America, Washington, DC, 29-31 March.

Mullan Harris, Kathleen, Greg J. Duncan, and Johanne Boisjoly. 2002. "Evaluating the role of 'nothing to lose' attitudes on risky behavior in adolescence," Social Forces 80(3): 1005-1039.

National Campaign to Prevent Teen Pregnancy (NCPTP). 1999. Peer Potential: Making the Most of How Teens Influence Each Other. Washington, DC: NCPTP.

National Institute of Allergy and Infectious Diseases (NIAID). 2001. Scientific Evidence on Condom Effectiveness for Sexually Transmitted Disease (STD) Prevention. Workshop summary proceedings, National Institutes of Health, Herndon, VA, 12-13 June 2000. 
Nichols, Douglas, Emile T. Woods, Deborah S. Gates, and Joyce Sherman. 1987. "Sexual behaviour, contraceptive practice, and reproductive health among Liberian adolescents," Studies in Family Planning 18(3): 169-176.

Pawelko, K. and A. Magafas. 1997. "Leisure well-being among adolescent groups: Time, choices, and self-determination," Parks and Recreation 32(7): 26-39.

Resnick, Michael D., Peter S. Bearman, Robert W. Blum, Carl E. Bauman, Kathleen M. Harris, Jo Jones, Joyce Tabor, Trish Beuhring, Renee Seiving, Marcia Shaw, Marjorie Ireland, Linda H. Bearinger, and J. Richard Udry. 1997. "Protecting adolescents from harm," Journal of the American Medical Association 278(10): 823-832.

Reuters. 2001. "Teenage AIDS rate in South Africa easing-Official.” 12 March.

Richter, Linda. 1996. A Survey of Reproductive Health Issues among Urban Black Youth in South Africa. Pretoria: Society for Family Health.

Robinson, Amara, Lisanne Brown, and Kate Macintyre. 2001. "Two to tango: Focusgroup discussions among adolescents in KwaZulu-Natal Province, South Africa." Unpublished.

Roos, J., H. Pretorius, and M. Visser. 1995. Part 1: "A proposed strategy for changing high-risk sexual behaviour among students at tertiary institutions: A qualitative investigation with a view to developing a preventive programme," CHASA 6(2): $81-84$.

Rutenberg, Naomi, Cathrien Kehus-Alons, Lisanne Brown, Kate Macintyre, Anthea Dallimore, and Carol Kaufman. 2001. Transition to Adulthood in the Context of AIDS in South Africa: Report of Wave 1. New York: Population Council.

Rutter, M. 1993. "Resilience: Some conceptual considerations," Journal of Adolescent Health 14(8): 626-639.

Segil, E. and A. Sebastiani. 1999. "An integrated reproductive health \& business training program for youth." <http://www.pathfind.org/Project\%20Highlights/ inppares.html>. Accessed February 2001.

Singh, Susheela. 1998. "Adolescent childbearing in developing countries: A global review," Studies in Family Planning 29(2): 117-136. 
South African Department of Health. 2001. National Annual Survey of Antenatal Clinics 2000. Pretoria: South African Department of Health.

South African Medical Research Council (SAMRC), South African Department of Health (SADOH), and Macro International (MI). 1999. South African Demographic and Health Survey. Preliminary Report 1998. Pretoria, South Africa, and Calverton, MD: SAMRC, SADOH, and MI.

Steele, Fiona, Ian Diamond, and Doulao Wang. 1996. "The determinants of the duration of contraceptive use in China: A multilevel multinomial discrete-hazards modeling approach," Demography 33(1): 12-23.

Steele, Fiona, Sajeda Amin, and Ruchira T. Naved. 1998. "The impact of an integrated micro-credit program on women's empowerment and fertility behavior in rural Bangladesh," Policy Research Division Working Paper No. 115. New York: Population Council.

Steele, Fiona, Siân L. Curtis, and Minja Choe. 1999. "The impact of family planning service provision on contraceptive-use dynamics in Morocco," Studies in Family Planning 30(1): 28-42.

Tsui, Amy Ong. 1985. "Community effects on contraceptive use," in The Collection and Analysis of Community Data. Ed. John B. Casterline. Voorburg: International Statistical Institute.

UNAIDS. 2001. AIDS Epidemic Update. Geneva: UNAIDS and World Health Organization.

UNICEF. 1998. State of the World's Children, 1997. New York: UNICEF.

Varga, Christine. 1997. "Sexual decision-making and negotiations in the midst of AIDS: Youth in Kwazulu-Natal," Health Transition Review 7(2): 13-40.

__ 1999. "South African young people's sexual dynamics: Implications for behavioural responses to HIV/AIDS," in Resistances to Behavioural Change to Reduce HIV/AIDS in Predominantly Heterosexual Epidemics in Third World Countries. Eds. John C. Caldwell et al. Canberra: Health Transition Centre, National Center for Epidemiology and Population Health, Australian National University. 
Varga, Christine and L. Makubalo. 1996. "Sexual non-negotiation,” Agenda 28: 31-38.

Wood, Katharine and Rachel Jewkes. 1997. "Violence, rape, and sexual coercion: Everyday love in a South African township," Gender and Development 5(2): 4146.

Zabin, Laurie Schwab and Karungari Kiragu. 1998. "Health consequences of adolescent sexual and fertility behaviour in sub-Saharan Africa," Studies in Family Planning 29(2): 210-232. 


\title{
POLICY RESEARCH DIVISION WORKING PAPERS
}

\author{
Recent Back Issues
}

133 Mary Arends-Kuenning and Sajeda Amin, "The effects of schooling incentive programs on household resource allocation in Bangladesh."

134 John Bongaarts and Charles F. Westoff, "The potential role of contraception in reducing abortion."

135 John B. Casterline and Steven W. Sinding, "Unmet need for family planning in developing countries and implications for population policy."

*136 Carol E. Kaufman, Thea de Wet, and Jonathan Stadler, "Adolescent pregnancy and parenthood in South Africa."

*137 Valerie L. Durrant and Zeba A. Sathar, "Greater investments in children through women's empowerment: A key to demographic change in Pakistan?"

138 Sajeda Amin, Alaka Malwade Basu, and Rob Stephenson, "Spatial variation in contraceptive use in Bangladesh: Looking beyond the borders."
139 Geoffrey McNicoll, "Managing population-environment systems: Problems of institutional design."

140 Barbara S. Mensch, Barbara L. Ibrahim, Susan M. Lee, and Omaima ElGibaly, "Socialization to gender roles and marriage among Egyptian adolescents."

141 John Bongaarts and Elof Johansson, "Future trends in contraception in the developing world: Prevalence and method mix."

142 Alaka Malwade Basu and Sajeda Amin, "Some preconditions for fertility decline in Bengal: History, language identity, and an openness to innovations."

143 Zeba Sathar, Cynthia B. Lloyd, Cem Mete, and Minhaj ul Haque, "Schooling opportunities for girls as a stimulus for fertility change in rural $\mathrm{Pa}-$ kistan."

* No longer available 
144 John Bongaarts, "Household size and composition in the developing world."

145 John B. Casterline, Zeba A. Sathar, and Minhaj ul Haque, "Obstacles to contraceptive use in Pakistan: A study in Punjab."

146 Zachary Zimmer, Albert I. Hermalin, and Hui-Sheng Lin, "Whose education counts? The impact of grown children's education on the physical functioning of their parents in Taiwan."

147 Philomena Nyarko, Brian Pence, and Cornelius Debpuur, "Immunization status and child survival in rural Ghana."

148 John Bongaarts and Zachary Zimmer, "Living arrangements of older adults in the developing world: An analysis of DHS household surveys."

149 Markos Ezra, "Ecological degradation, rural poverty, and migration in Ethiopia: A contextual analysis."
150 Cynthia B. Lloyd, Sahar El Tawila, Wesley H. Clark, and Barbara S. Mensch, "Determinants of educational attainment among adolescents in Egypt: Does school quality make a difference?"

151 Barbara S. Mensch, Paul C. Hewett, and Annabel Erulkar, " The reporting of sensitive behavior among adolescents: A methodological experiment in Kenya."

152 John Bongaarts, "The end of the fertility transition in the developed world."

153 Mark R. Montgomery, GebreEgziabher Kiros, Dominic Agyeman, John B. Casterline, Peter Aglobitse, and Paul Hewett, "Social networks and contraceptive dynamics in southern Ghana."

154 Paul C. Hewett and Mark R. Montgomery, "Poverty and public services in developing-country cities." 
155 Zachary Zimmer, Linda G. Martin, and Ming-Cheng Chang, "Changes in functional limitations and survival among the elderly in Taiwan: 1993, 1996, and 1999."

156 John Bongaarts and Griffith Feeney, "How long do we live?"

157 Zachary Zimmer and Sovan Kiry Kim, "Living arrangements and socio-demographic conditions of older adults in Cambodia."
158 Geoffrey McNicoll, "Demographic factors in East Asian regional integration."

159 Carol E. Kaufman, Shelley Clark, Ntsiki Manzini, and Julian May, "How community structures of time and opportunity shape adolescent sexual behavior in South Africa." 